\title{
Nursing intervention focusing on health promotion behaviors in adult cancer patients: a scoping review
}

\author{
Intervenção de enfermagem com foco em comportamentos de promoção \\ da saúde em pacientes adultos com câncer: uma revisão de escopo \\ Intervención de enfermería centrada en los comportamientos de promoción \\ de la salud en pacientes adultos con cáncer: una revisión del alcance
}

How to cite this article:

Peixoto NMSM, Peixoto TASM, Pinto CAS, Santos CSVB. Nursing intervention focusing on health promotion behaviors in adult cancer patients: a scoping review. Rev Esc Enferm USP. 2021;55:e03673. doi: https://doi.org/10.1590/S1980-220X2019039403673

Nuno Miguel dos Santos Martins Peixoto $^{1}$

\section{iD Tiago André dos Santos Martins} Peixoto $^{1}$

Cândida Assunção Santos Pinto ${ }^{2}$

Célia Samarina Vilaça de Brito Santos ${ }^{2}$

${ }^{1}$ University of Porto, Abel Salazar Institute of Biomedical Sciences, Porto, Portugal.

${ }^{2}$ Nursing School of Porto, Porto, Portugal.

\begin{abstract}
Objective: This review aims to map and provide an overview of literature concerning nursing strategies and intervention programs that promote healthy behaviors in cancer patients. Method: A scoping review was conducted using the methodological framework developed by Joanna Briggs Institute and preferred reporting items for systematic reviews and meta-analyses extension for scoping reviews. Twelve databases were searched (2012-2019). Retrieved data included descriptive analyses exploring studies' methodological characteristics and results. Results: From 1589 studies, 12 were included. Most studies included patients on survivorship period $(\mathrm{n}=10)$ and selected intervention strategies focusing patient's knowledge and awareness $(n=8)$. Educational sessions were supported by behavioral change reinforcements and motivational incentives. Only two of the considered studies analysed intervention cost effectiveness, but none disclosed intervention-related costs. Conclusion: Nursing interventions are effective in promoting health behaviors when include health education and encouragement towards change. Survivorship is the perfect time for health promotion. Nurses can be considered health promoters, by encouraging health education and enhance survivor's motivation.
\end{abstract}

DESCRIPTORS

Neoplasm; Oncology Nursing; Health Promotion; Health Education; Review.
Corresponding author:

Nuno Miguel Peixoto

Escola de Enfermagem do Porto

Rua Dr. António Bernardino de Almeida

4200-072 - Porto, Portugal

nunomiguelpeixoto@gmail.com
Received: $12 / 25 / 2019$

Approved: 05/29/2020 


\section{INTRODUCTION}

Cancer is one of the biggest social threats and a public health problem worldwide, affecting all ages ${ }^{(1)}$. More than 18 million new cases of cancer are diagnosed every year ${ }^{(2)}$. Between 2015 and 2018, approximately 9 million deaths were attributed to cancer each year, representing $15 \%$ of all deaths in the world ${ }^{(2-3)}$. Due to its increasing incidence and mortality, there is also a growing social burden associated with the disease, which causes a high physical, emotional and financial pressure over individuals, families, communities and health services ${ }^{(4)}$.

According to health services, cancer is a serious problem. In 2014, approximately 87.8 billion dollars were spent in the U.S. in cancer-related healthcare ${ }^{(5)}$. On an individual basis the problem is not smaller, as cancer is considered a chronic illness which impacts every dimension of patients' lives and leads to feelings of great threat, uncertainty and insecurity about their health ${ }^{(6-7)}$. Recognizing cancer as a chronic illness implies that efforts and resource allocation are not exclusively directed at diagnosis and treatment, but also at promoting rehabilitation and quality of life (QoL) for cancer survivors ${ }^{(8)}$.

Cancer patients have their QoL significantly compromised by the disease and are at higher risk of recurrence and of developing new cancers compared to the general population $^{(9-10)}$. On the other hand, for many patients, cancer works as an encouragement for health-promoting lifestyle changes. It is imperative to help cancer patients manage their disease and improve their health condition and QoL. Cancer-related health promotion and disease management are not the same. Disease management refers to interventions or care directed at controlling and managing cancer, emphasizing clinical aspects and disease control. On the other hand, health promotion intends for cancer patients to have an active role in their healthcare, incorporating several self-initiated health behaviors, and to enhance their responsibility and commitment towards a healthy lifestyle ${ }^{(11)}$. Health promotion is the process of enabling people to increase control over, and improve their health ${ }^{(12)}$, and has been described as a key concept in nursing practice.

Some authors sought to integrate nursing with behavioral sciences in the work they developed ${ }^{(13)}$. Nurses role comprise the building of a favourable environment for ideal health expression and well-being. It means that nurses should have an active role in providing guidance for survivors to adopt healthy lifestyle behaviors ${ }^{(14)}$, helping them to develop knowledge and teach skills required to achieve their goals ${ }^{(15)}$.

Currently, there is an international demand for helping cancer patients to make permanent lifestyle changes during and after cancer, including some guidelines for cancer survivors based on nutrition and physical activity ${ }^{(10)}$. Nevertheless, some reviews pointed that cancer support services have low participation and there is an inadequate referral of survivors to cancer support services, especially because providers are not aware of the services properly and not value them enough ${ }^{(15)}$. In Portugal, the majority of studies still focusing on preventing, diagnosing and treating the cancer, and there are none nursing intervention focusing on health promotion behaviors known and applied. Therefore, it is imperative review, describe and analyzed interventions performed by nurses all over the world to help further investigation.

The aim of this review is to map and provide an overview of recent literature concerning nursing strategies and intervention programs that promote healthy behaviors in cancer patients. This is the first step of a bigger study aiming to develop a nursing educational intervention to increase health promotion behaviors on cancer survivors, based on the Medical Research Council recommendations for development and evaluation of complex interventions ${ }^{(16)}$.

The research question for this review was: "What is known in the existing scientific literature about nursing strategies and interventions programs focused on health promotion behaviors in adult cancer patients?" The aims, inclusion criteria and methodological approach for this review were detailed and documented in a prior study protocol.

\section{METHOD}

\section{StUdi DESIGN}

A scoping review was conducted using the methodological framework developed by Joanna Briggs Institute Reviewers' Manual 2015 - Methodology for JBI Scoping Reviews and Preferred Reporting Items for Systematic reviews and Meta-Analyses extension for Scoping Reviews (PRISMA-ScR) Checklist for data organization (see Supplementary File 1). The authors chose to conduct a scoping review because a systematic review would not be effective: systematic reviews address relatively precise questions, such as effectiveness of a particular intervention based on a precise set of outcomes ${ }^{(17)}$. This scoping review sought to examine a range of nursing interventions directed at promoting health behaviors and to map and clarify key concepts underlying this research area.

The review process comprised six sequential steps: (I) identification of the research question; (II) identification of relevant studies; (III) study selection; (IV) data extraction and charting; (V) collation, summary and report of results; and (VI) optional consulting with stakeholders ${ }^{(18)}$. Step VI was omitted because we will validate the scoping review findings with the stakeholders in other study.

\section{Data collection}

The research question (Step I) was already mentioned. For identifying the relevant studies (Step II) we selected twelve electronic databases were searched using appropriate search terms. A database search was initially conducted using the free-term query "cancer", "nursing" and "health promotion", aiming to identify relevant articles and most frequently used keywords. Then, a Boolean search phrase was defined using Medical Subject Heading (MeSH) terms and free text words. Boolean operators "OR" and "AND" and the tool "**" were used to create new variations of the same word, thus expanding the search. 
Through EBSCOhost Web ${ }^{\circledR}$ search engine, a search was performed in CINAHL Complete ${ }^{\circledR}$, MEDLINE with Full Text ${ }^{\circledR}$, Academic Search Complete ${ }^{\circledR}$, Business Source Complete $^{\circledR}$, Educational Resource Information Center ${ }^{\circledR}$ (ERIC), Library, Information Science \& Technology Abstracts ${ }^{\circledR}$ (LISTA), MedicLatina ${ }^{\circledR}$, Psichology \& Behavioral Sciences Collection ${ }^{\circledR}$, Regional Business News ${ }^{\circledR}$ and SPORTDiscus with Full Text ${ }^{\circledR}$ databases with the following Boolean phrase: ((("Neoplasms") OR (“Cancer") OR ("Cancer patient") NOT ("Child")) AND ("Health Promotion") AND (("Nursing") OR ("Nursing care"))). The following active filters were used: Published Date - 2012.01.01-2019.01.31. Afterwards, Cochrane Library ${ }^{\circledR}$ was searched with a search engine-adapted Boolean phrase: (Neoplasms OR Cancer OR Cancer patient NOT Child) AND (Health Promotion) AND (Nursing OR Nursing care); Publication from 2012.01.01 to 2019.01.31; Search all text.

\section{SELECTION CRITERIA}

Search strategy was limited by publication year, as the authors intended to narrow the search to the most recent publications on the topic (i.e. last 7 years). Due to the high specificity of interventions on these patient populations, studies involving children and/or adolescents were excluded, and so were studies concerning interventions not performed by nurses. All types of oncology patients were considered, except those on the palliative setting. Although search language was English, studies written in both English and Portuguese were considered. The present review also included studies that met inclusion criteria previously identified through additional searches, study reference lists and grey literature. Search strategy was not restricted to one type of study in particular, including all scientific studies regardless of study design.

After study search, their selection was conducted (Step III). First, duplicated citations were removed through a reference's manager software $\left(\right.$ Zotero $\left.{ }^{\circledR}\right)$. Then titles and abstracts were scanned to identify relevant articles. Finally, full text of selected articles was critically reviewed to identify articles meeting predefined inclusion criteria. Abstract and full-text review and data extraction were conducted by two independent investigators. Disagreements between the two authors were resolved by listening a third member of the research team.

\section{DatA ANALYSIS AND TREATMENT}

Selected studies were charted and analysed in two different phases (Step IV). On the first phase, a descriptive analysis was performed exploring studies' methodological characteristics (aim(s), sample, design) and results (including a descriptive statistical analysis by year of publication and geographic distribution). On the second phase, evidence retrieved was assembled in five categories related with nursing interventions: procedures, mechanisms of change, outcome assessment measures, effectiveness and cost effectiveness. Evidence tables were developed to organize data, according to the five categories above. After that, the implications of the study findings for practice and future research were identified and discussed (Step V).

\section{RESULTS}

A total of 1589 studies were initially retrieved, of which 299 were duplicates and therefore removed. Twenty-three studies retrieved from the grey literature were further included. After title and abstract analysis, 1094 studies were excluded for not specifically focusing health promotion or cancer patients. After full-text review, 184 studies were further excluded for not meeting inclusion criteria. Overall, 12 studies were selected for data extraction and analysis (Figure 1).

Overall, 12 research articles were included in the present review. From these, eight are quantitative studies (two randomized controlled trials, two clinical trials with preand post-intervention assessment, one quasi-experimental pilot study and three study protocols), three are review articles and one is a discussion paper. Retrieved studies were dated between 2012 and 2017 and conducted in the U.S. $(n=6)$, Australia $(n=4)$, South Korea $(n=1)$ and Hong Kong $(n=1)$. Individuals with different types of tumor $(n=8)$ were included, including breast $(n=2)$, gastrointestinal $(n=1)$ and hematological $(n=1)$ tumors. Most studies $(n=10)$ included cancer survivors, defined as cancer patients who concluded treatment with curative intent (chemotherapy, radiotherapy or other) without disease evolution or relapse. Only two studies included cancer patients regardless of disease stage. Six quantitative studies (50\%) included large samples (>50 participants).

Analysis of selected studies revealed that they all described interventions performed or planned by nurses. Despite the fact that most intervention programs designed by nurses simultaneously include several health promotion behavior measures, including exercise, nutrition, alcohol consumption, and weight and stress management ${ }^{(19-26)}$. Other programs specifically focus particular behaviors, such as smoking cessation ${ }^{(27)}$ and physical activity ${ }^{(28-30)}$.

The main characteristics of included studies, namely their aim(s), sample, design, intervention description and duration are depicted in Chart 1. 
Description of included studies
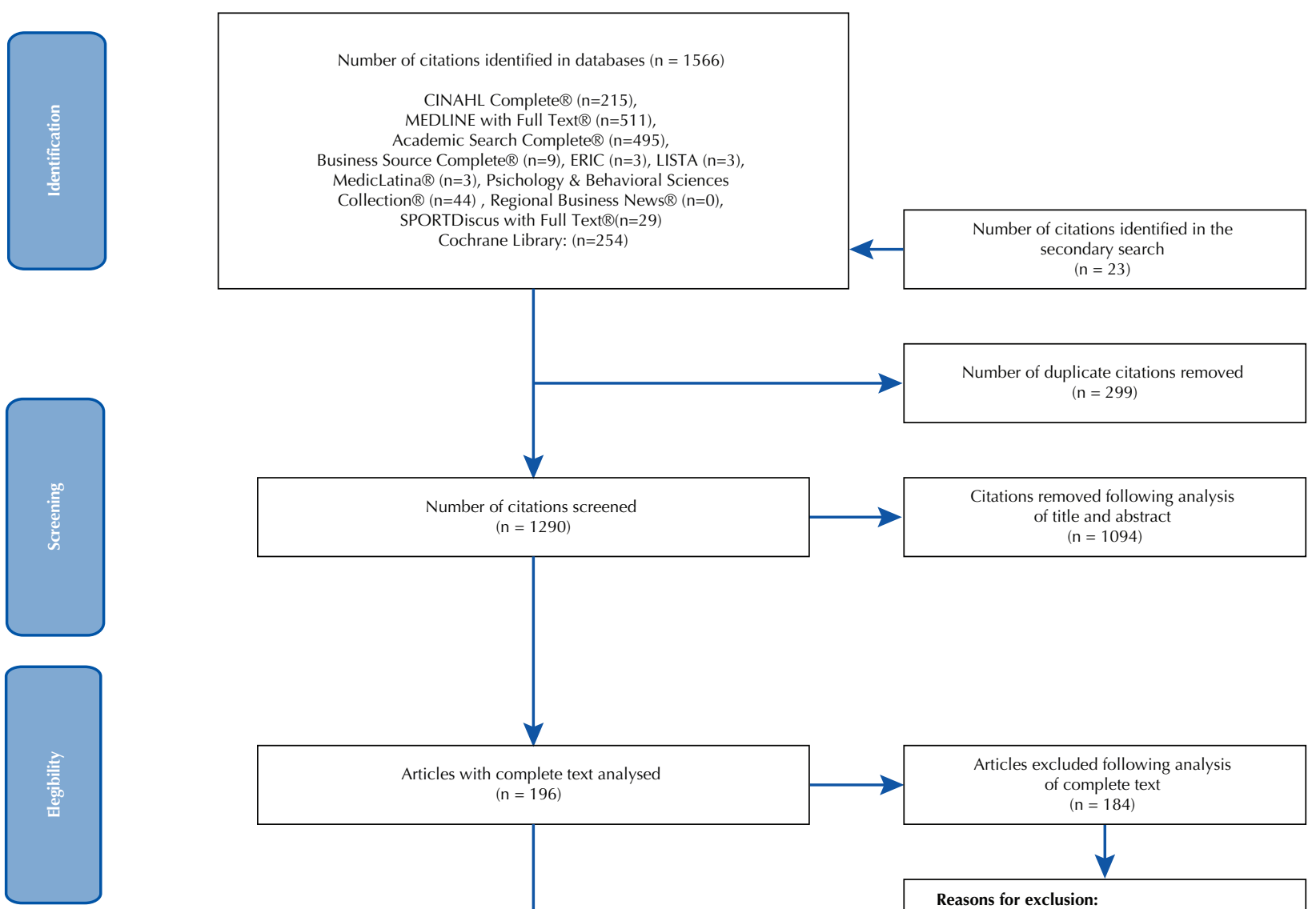

$$
(\mathrm{n}=1094)
$$
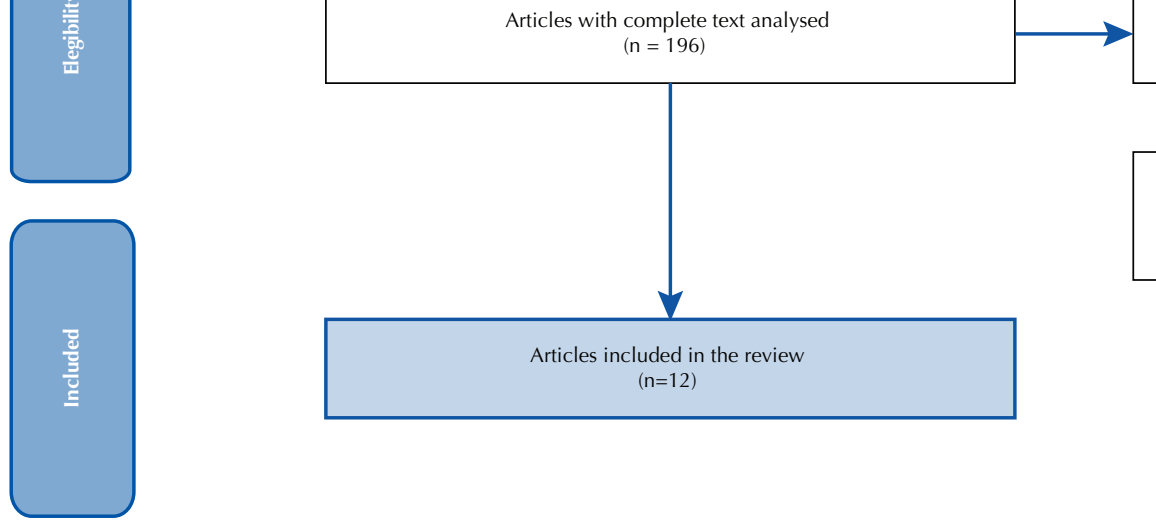

Articles excluded following analysis of complete text

$(n=184)$

Figure 1 - Study identification and inclusion process: PRISMA Diagram Flow.

Chart 1 - Characteristics of studies included in the review.

\begin{tabular}{|c|c|c|c|c|}
\hline Study & $\operatorname{Aim}(s)$ & Sample and design & Intervention description & $\begin{array}{l}\text { Intervention } \\
\text { duration }\end{array}$ \\
\hline $\begin{array}{l}\text { Study } 1 \text { (S1) } \\
\text { Yun et al., } \\
2017^{(19)} \\
\text { South Korea }\end{array}$ & $\begin{array}{l}\text { To evaluate the potential benefits } \\
\text { of the Leadership and Coaching } \\
\text { for Health (LEACH) program on } \\
\text { physical activity (PA), dietary habits, } \\
\text { and distress management in cancer } \\
\text { survivors. }\end{array}$ & $\begin{array}{l}\text { Randomized controlled } \\
\text { trial. } \\
\text { A total of } 248 \text { cancer } \\
\text { survivors who completed } \\
\text { primary cancer treatment } \\
\text { (in situ, localized, or } \\
\text { regional with a favorable } \\
\text { prognosis) within the last } 24 \\
\text { months for breast, stomach, } \\
\text { colon (other than rectal), } \\
\text { and lung cancer within } \\
18 \text { months of completion } \\
\text { of primary treatment were } \\
\text { included. }\end{array}$ & $\begin{array}{c}\text { First, patients were given a 1-h health } \\
\text { education workshop (physical activity, } \\
\text { dietary habits, and distress management) } \\
\text { and a 3-h leadership workshop (Seven } \\
\text { Habits of Highly Effective People with } \\
\text { Cancer). Next, the Intervention group } \\
\text { was also offered individual coaching } \\
\text { by telephone for a } 24 \text {-week period. A } \\
\text { total of } 16 \text { sessions of tele-coaching } \\
\text { were conducted: } 30 \text { min per week for } \\
12 \text { sessions, } 30 \text { min per } 2 \text { weeks for } 2 \\
\text { sessions, and } 30 \text { min per month for } 2 \\
\text { sessions were offered for the intervention } \\
\text { group. }\end{array}$ & $\begin{array}{c}24 \text { weeks, of } \\
\text { which } 1 \text { were } \\
\text { dedicated to } \\
\text { educational } \\
\text { strategies. }\end{array}$ \\
\hline
\end{tabular}

Continue... 


\begin{tabular}{|l|l}
\hline Study & Aim(s) \\
\hline & \\
& \\
& \\
Study 2 (S2) & $\begin{array}{l}\text { To evaluate the integration of an } \\
\text { evinin et al., } \\
\text { for cancer survivors into an existing } \\
\text { Australia }\end{array}$ \\
telephone cancer information \\
and support service delivered by \\
the Australian state-based Cancer \\
Councils.
\end{tabular}

Study protocol of a randomized clinical trial with a pre- and a postintervention measurement The HLaC (Healthy Living after Cancer) dissemination and implementation study uses a single-group, pre-post-test study design. Eligible participants were adults who completed cancer treatment with curative intent.
A semi-structured approach and tailored to each participant, with an initial focus on targets in areas that the participant is most motivated and confident to change.

Participants are encouraged to: begin

with a focus on increasing physical activity,

identifying enjoyable activities with gradual increases in physical activity, do resistance exercise (2-3 sessions/week), increasing intake of vegetables, fruit and whole grains, reducing intake of foods high in added sugars and fat limiting portion size and improving dietary quality. The intervention is delivered in three phases, with weekly, fortnightly and then monthly calls.
28 weeks, of which 4 will be dedicated to educational strategies.
Study 3 (S3)

Gates,

Seymour \&

Krishnasamy,

2012(21)

Australia
To establish whether receiving a health promoting intervention from a specialist cancer nurse is able to improve Hodgkin lymphoma

(HL) survivors' knowledge of and motivation to adopt health promoting behaviors and is able to: improve HL survivors' perceptions of their health status, reduce patientreported unmet information needs in relation to Late Effects (LE) and reduce health worries associated with knowledge of the risk of developing LE.

\section{Quasi-experimental pilot study.}

A total of 30 people who

had received curative treatment for $\mathrm{HL}$ were recruited from referral lists to the hematology late effects clinic at Peter Mac. Additionally, 30 healthy controls matched for age and gender were recruited to provide data at baseline only, to help contextualize

HL survivor data at study entry.
The nurse-led consultations include an education package tailored to Hodgkin lymphoma survivor's health needs, screening for emotional distress and delivery of an individualized survivorship care plan.
14 weeks, of which 2 were dedicated to educational strategies.
To identify components of efficacious interventions for multiple health behavior change (MHBC) in cancer survivors and individuals at high risk of developing cancer and to identify components of efficacious interventions on changing multiple health behaviors, determine effect sizes, and address any gaps that may exist on this topic that need to be addressed in future research.
Literature review article; 13 articles were included
A lot of 13 interventions were described: Lifestyle intervention (LI), FRESH START interventions (3), Telephone counseling and mailed print material diet and exercise intervention, Educational intervention (El) using I-Change Model, CanChange intervention, Project PREVENT, NC STRIDES Health communication interventions, Lifestyle program, Tailored telephone counseling intervention, Psychological interventions (2).
To describe and evaluate riskadapted visits (RAV) provided by LIFE Cancer Survivorship Program at North Shore University Health

System and facilitated by an

Oncology nurse in promoting

Study 5 (S5) Rosenberg et al., 2016 $6^{(23)}$

United States individualized health care and selfmanagement during survivorship transition.
Clinical trial with a post-

intervention measurement.

Patients completed a post-

RAV questionnaire at their

RAV and another $\geq 1$ year after their RAV.

1713 RAVs, mostly for breast cancer, occurred from January 2007 to March

2014. One thousand six hundred fifteen (1615) "dayof" post-RAV questionnaires were completed.
The intervention includes a face-toface visit provides a 1-hour time frame for the provision and discussion of a personalized SCP and a monthly group education seminars on topics tailored specifically to RAV participants regarding

lifestyle (nutrition/fitness), genetics, sexuality, employment, cognition and lymphedema.
1 year, of which 10 months were dedicated to educational strategies.
Study 6 (S6)

Anderson et al., $2017^{(24)}$

Australia
To determine the efficacy and cost effectiveness of a multimodal, digitized lifestyle intervention The Women's Wellness after Cancer Program (WWACP) - aiming to enhance health-related quality of life in women previously treated for breast, gynecological, or blood cancers.
Study protocol of a randomized controlled trial.

A total of 330 women were recruited within 24 months of completion of chemotherapy (primary

or adjuvant) and/or radiotherapy.
This multi-modal intervention comprises a virtually-delivered health professional consultations, an interactive web interface (including podcasts), an interactive electronic book (iBook) which provides detailed intervention instructions and supports participants to log relevant health and lifestyle information into a journal.
12 weeks, of which 8 will dedicated to educational strategies. 


\begin{tabular}{|c|c|c|c|c|}
\hline Study & $\operatorname{Aim}(s)$ & Sample and design & Intervention description & $\begin{array}{l}\text { Intervention } \\
\text { duration }\end{array}$ \\
\hline $\begin{array}{l}\text { Study } 7 \text { (S7) } \\
\text { Tramm, } \\
\text { McCarthy \& } \\
\text { Yates, 2012 } \\
\text { Australia }\end{array}$ & $\begin{array}{l}\text { To discuss the use of the Precede- } \\
\text { Proceed model when investigating } \\
\text { health promotion options for breast } \\
\text { cancer survivors; to understand } \\
\text { health behaviors of female cancer } \\
\text { survivors in order to plan a health } \\
\text { promotion program that optimizes } \\
\text { their posttreatment health. }\end{array}$ & $\begin{array}{l}\text { Discussion Paper. } \\
\text { Interview data from the } \\
\text { breast cancer survivor cohort } \\
\text { was used to illustrate the use } \\
\text { of Precede-Proceed model } \\
\text { in this nursing research } \\
\text { context. Interview data } \\
\text { was collected from June to } \\
\text { December 2009. Medline, } \\
\text { CINAHL, Psychlnfo and } \\
\text { PsychExtra literature was } \\
\text { also searched until } 2010 \\
\text { to analyse data from other } \\
\text { theoretical perspectives. }\end{array}$ & No intervention & --- \\
\hline $\begin{array}{l}\text { Study } 8 \text { (S8) } \\
\text { Meraviglia et } \\
\text { al., } 2013^{(26)} \\
\text { United States }\end{array}$ & $\begin{array}{l}\text { To adapt, refine and implement a } \\
\text { holistic intervention to promote the } \\
\text { use of health-promoting behaviors } \\
\text { of cancer survivors after their initial } \\
\text { therapy. }\end{array}$ & $\begin{array}{l}\text { Randomized control trial } \\
\text { of a health promotion } \\
\text { intervention that was } \\
\text { implemented for low- } \\
\text { income cancer survivors. } \\
\text { A total of } 51 \text { cancer } \\
\text { survivors were initially } \\
\text { enrolled in } 2 \text { cohorts ( } 29 \\
\text { intervention, } 22 \text { control). }\end{array}$ & $\begin{array}{l}\text { The innovative 3-component } \\
\text { intervention included (a) development of } \\
\text { one-on-one participant-provider support } \\
\text { relationships (individualized support to } \\
\text { facilitate benefits and reduce barriers to } \\
\text { attending classes and adopting health- } \\
\text { promoting behavior); (b) attendance at } 6 \\
\text { weekly classes (acquisition of knowledge } \\
\text { about cancer, cancer survivorship, } \\
\text { surveillance, and smoking cessation; } \\
\text { stress management; physical activity/ } \\
\text { exercise; nutrition; and spiritual growth); } \\
\text { and (c) follow-up support for } 2 \text { months } \\
\text { to encourage use of health-promoting } \\
\text { behaviors (telephone calls) }\end{array}$ & $\begin{array}{l}14 \text { weeks, of } \\
\text { which } 6 \text { will } \\
\text { dedicated to } \\
\text { educational } \\
\text { strategies. }\end{array}$ \\
\hline $\begin{array}{l}\text { Study } 9 \text { (S9) } \\
\text { Li et al., } \\
2015^{(27)} \\
\text { Hong Kong }\end{array}$ & $\begin{array}{l}\text { To test the effectiveness of a } \\
\text { smoking cessation intervention using } \\
\text { risk communication approach to } \\
\text { help cancer patients quit smoking } \\
\text { and improve their health-related } \\
\text { quality of life. }\end{array}$ & $\begin{array}{l}\text { Study protocol of a cluster } \\
\text { randomized controlled trial. } \\
\text { Inclusion criteria included } \\
\text { patients who smoked } \\
\text { weekly in the past } 6 \\
\text { months, diagnosed with } \\
\text { smoking-related cancers, } \\
\text { diagnosed with cancer } \\
\text { for at least } 6 \text { months, in } \\
\text { all disease stages, aged } \\
18 \text { or above, and able to } \\
\text { communicate in Cantonese. }\end{array}$ & $\begin{array}{l}\text { Apart from receiving a generic self-help } \\
\text { smoking cessation booklet, subjects will } \\
\text { receive: a) a specifically designed risk } \\
\text { communication leaflet from oncologists/ } \\
\text { oncology nurses during the medical } \\
\text { consultation (including risk of continued } \\
\text { smoking), } \\
\text { b) a patient-centered motivational } \\
\text { intervention by an experienced } \\
\text { nurse counsellor focusing on risk } \\
\text { communication based on self-regulation } \\
\text { model of illness for cancer patients, c) at } \\
\text { least one boost up telephone intervention } \\
\text { within one week, and d) another } \\
\text { telephone intervention within one month } \\
\text { by nurse counsellor (10-15 min). }\end{array}$ & $\begin{array}{c}5 \text { weeks, of } \\
\text { which } 1 \text { will } \\
\text { be dedicated } \\
\text { to educational } \\
\text { strategies. }\end{array}$ \\
\hline $\begin{array}{l}\text { Study } 10 \\
\text { (S10) } \\
\text { Hirschey et } \\
\text { al., 2016 } 288 \\
\text { United States }\end{array}$ & $\begin{array}{l}\text { To test effects of gain-framed versus } \\
\text { loss-framed mailed brochures on } \\
\text { increasing physical activity (PA) } \\
\text { among colorectal cancer (CRC) } \\
\text { survivors. }\end{array}$ & $\begin{array}{l}\text { Randomized clinical trial } \\
\text { with a pre- and a post- } \\
\text { intervention measurement } \\
\text { (baseline, } 1 \text { month, and } 12 \\
\text { months post-intervention). } \\
\text { A total of } 148 \text { inactive CRC } \\
\text { survivors who completed } \\
\text { primary therapy were } \\
\text { included: aged } 18 \text { years } \\
\text { and older with diagnoses of } \\
\text { early-stage (I-II), who had } \\
\text { adequately recovered from } \\
\text { surgical and completed } \\
\text { adjuvant therapy within } \\
\text { the previous six months to } \\
\text { five years; no evidence of } \\
\text { recurrence; no preexisting } \\
\text { medical condition(s) that } \\
\text { precluded adherence to an } \\
\text { unsupervised PA program; } \\
\text { approved for contact by their } \\
\text { oncologic care physician; } \\
\text { community dwelling. }\end{array}$ & $\begin{array}{l}\text { All participants received a single-page } \\
\text { tri-folded educational brochure with an } \\
\text { insert that had four main sections: (a) } \\
\text { tips on how to become more physically } \\
\text { active (e.g., get friends and family to } \\
\text { help, blocking off time on your daily } \\
\text { calendar), with examples of activities of } \\
\text { moderate-intensity PA; (b) description } \\
\text { of other diseases for which CRC survi- } \\
\text { vors are at increased risk (e.g., heart } \\
\text { disease, dia- betes, second cancers) } \\
\text { and the protective influence of PA on } \\
\text { these comorbid conditions; (c) descrip- } \\
\text { tion and results of two epidemiologic } \\
\text { studies that showed a significant inverse } \\
\text { relationship between self-reported PA } \\
\text { and risk of cancer-specific mortal- ity } \\
\text { and all-cause mortality in CRC survivors; } \\
\text { and (d) a summary of benefits of being or } \\
\text { disadvantages of not being PA. }\end{array}$ & $\begin{array}{l}1 \text { day, entirely } \\
\text { dedicated to } \\
\text { educational } \\
\text { strategies. }\end{array}$ \\
\hline
\end{tabular}




\begin{tabular}{|c|c|c|c|c|}
\hline Study & $\operatorname{Aim}(s)$ & Sample and design & Intervention description & $\begin{array}{l}\text { Intervention } \\
\text { duration }\end{array}$ \\
\hline $\begin{array}{l}\text { Study } 11 \\
\text { (S11) } \\
\text { Loprinzi \& } \\
\text { Lee, 2014 } \\
\text { United States }\end{array}$ & $\begin{array}{l}\text { To review the existing literature } \\
\text { on the relation between physical } \\
\text { activity and health outcomes among } \\
\text { cancer survivors; identify evidence- } \\
\text { based strategies to promote physical } \\
\text { activity among this population; and } \\
\text { conduct an epidemiologic study } \\
\text { based on gaps from the literature } \\
\text { review, examining the association } \\
\text { between physical activity and } \\
\text { various biologic markers. }\end{array}$ & $\begin{array}{l}\text { Literature Review and } \\
\text { Epidemiologic Examination. } \\
\text { Studies were examined } \\
\text { through a systematic } \\
\text { review process. In the } \\
\text { epidemiologic study, } 227 \\
\text { adult cancer survivors } \\
\text { wore an accelerometer } \\
\text { for four days or longer, } \\
\text { with biologic markers (e.g. } \\
\text { cholesterol) assessed from a } \\
\text { blood sample. }\end{array}$ & (no intervention) & --- \\
\hline $\begin{array}{l}\text { Study } 12 \\
\text { (S12) } \\
\text { Demark- } \\
\text { Wahnefried et } \\
\text { al., 2017(30) } \\
\text { United States }\end{array}$ & $\begin{array}{l}\text { To summarize key topics addressed } \\
\text { in a recent National Academies of } \\
\text { Science, Engineering, and Medicine } \\
\text { workshop entitled "Incorporating } \\
\text { Weight Management and Physical } \\
\text { Activity Throughout the Cancer Care } \\
\text { Continuum". }\end{array}$ & $\begin{array}{l}\text { Literature review. } \\
\text { The study collected } 23 \\
\text { articles that included } \\
\text { interventions for Weight } \\
\text { Management in Cancer } \\
\text { Survivors. }\end{array}$ & (too many interventions were described) & --- \\
\hline
\end{tabular}

\section{Procedures}

The theoretical framework supporting nursing interventions as a means to increase health promotion behaviors on cancer patients retrieved from this analysis is very heterogeneous. However, some consistency in selected theories could be found. The Social Cognitive Theory (SCT) $(1986)^{(20,24,29)}$, the Transtheoretical Model (TTM) (1983) ${ }^{(19,27)}$, the Theory of Planned Behavior (TPB) (1991) ${ }^{(27-28)}$ and the Revised Health Promotion Model (RHPM) (1996) ${ }^{(21,26)}$ were the most frequently employed theoretical models. Additionally, the Self-Efficacy Theory (1997) ${ }^{(26)}$ and the Self-Regulation Model of Illness (SRMI) (1980) ${ }^{(27)}$ were also used. Despite most studies mentioned the theoretical framework underlying their intervention programs $(n=8,66.7 \%)$, some studies $(n=2,16.7 \%)$ based their intervention on specific programs, such as the Living in the Future (LIFE) Cancer Survivorship Program at North Shore University Health System ${ }^{(23)}$ and the Precede-Proceed Model of Health Program Planning ${ }^{(25)}$. Amongst studies included in the present review, two were not considered in this analysis due to the plethora of interventions used.

Regarding nursing interventions, eight quantitative studies selected intervention strategies focusing patient's knowledge and awareness, especially through health education ${ }^{(19-21,23-24,26-28)}$. Besides health education, other interventional strategies were adopted, including (i) development of support relationships ${ }^{(26)}$; (ii) development of a care plan focusing health promotion and highlighting the need to adopt health behaviors and how to accomplish that; (iii) development of a strategy for patient reintegration into the primary care setting; (iv) encouraging cancer survivors to take an active role in wellness pursuit; and (v) connecting cancer survivors to community resources able to assist them in cancer emotional, physical and psychosocial issues ${ }^{(21,23)}$. Three studies emphasized the provision and discussion of a personalized care plan with individual goals as a key measure $^{(21,23-24)}$.
A detailed analysis of the duration of interventions in each of the eight quantitative studies analysed were done (Chart 1). Interventions varied between one day/moment and 1 year. Intervention programs had an average duration of 21,3 weeks and three of selected studies had a duration of 12 to 14 weeks. The shortest intervention consisted of delivering a single-page tri-folded educational brochure to encourage colorectal cancer survivors to increase physical activity ${ }^{(28)}$. The longest intervention consisted of a risk-adapted visit (RAV) combined with ten monthly group education seminars ${ }^{(23)}$.

Regarding educational strategies documented in the nine nursing intervention programs, three were group sessions ${ }^{(19,23,26)}$, four were individual appointments - two faceto-face ${ }^{(21,27)}$, one via telephone ${ }^{(20)}$ and one virtual ${ }^{(24)}$ and one consisted in the distribution of an educational brochure ${ }^{(28)}$. Three studies combined educational sessions with other educational materials, such as an interactive iBook and journal, web interface and podcasts ${ }^{(24)}$, a supplementary survival guide $^{(23)}$ and an informative booklet ${ }^{(27)}$. Group sessions had disparate characteristics, with one program comprising only one session and the other two programs including six to ten sessions ranging from 1 to 2.5 hours each.

Educational sessions were supported by behavioral change reinforcements and incentives. In addition to direct contact with cancer patients, six studies used telephone calls (10 to 30 minutes) to forge a relationship with the individuals and reinforce the initial educational interventions. For this purpose, nurses performed a series of interventions, which included: (i) individually coaching patients by telephone to encourage their health behaviors ${ }^{(19)}$; (ii) performing telephone calls to encourage practice, consolidation and maintenance of new health behaviors ${ }^{(20)}$; (iii) performing telephone follow-up interventions to assess patient progress, identify barriers to behavioral change, engage patients in the process (enhancing their self-efficacy) and identify individual barriers and facilitators $^{(27)}$; (iv) performing telephone nurse-led consultations to reinforce interventions and identify and address any new 
concerns $^{(21)}$; (v) performing phone coaching interventions to review program plans and goals, develop a personal action plan, identify barriers and self-monitoring ${ }^{(24)}$; and (vi) performing a follow-up support telephone call to encourage the use of health-promoting behaviors, express concern about participant's health status and answer pertinent questions ${ }^{(26)}$.

Programs focusing interventions complementary to educational strategies used three hours of leadership workshop (Seven Habits of Highly Effective People with Cancer) ${ }^{(19)}$; 15 to 30 minutes of patient-centered motivational intervention by an experienced nurse counsellor focusing on (i) risk communication based on self-regulation model of illness for cancer patients and (ii) the stage-matched smoking cessation intervention which aims to (a) increase awareness on the need to quit smoking, (b) motivate and increase confidence in the ability to quit, (c) set a quit plan and boost patient's self-efficacy to resist smoking and (d) discuss possible withdrawal symptoms and relapse prevention strategies ${ }^{(27)}$; and one-hour visits to discuss and develop a Survivorship Care Plan (SCP) encouraging cancer survivors to take an active role in self-wellness pursuit ${ }^{(23)}$.

\section{MeChanisms of Change}

Studies included in this review seem to coherently emphasize the relevance of motivation for the development and maintenance of new health behaviors and subsequent health improvement in cancer patients ${ }^{(20-22,24-25,27-28,30)}$. The Study 2 intended to build motivation for change ${ }^{(20)}$. In the study, nursing interventions were tailored to each participant, with an initial focus on areas in which they feel most motivated and confident to change. The Study 9 planned a patient-centered motivational intervention implemented by an experienced nurse counsellor to increase awareness on the need to change and motivate to quit smoking ${ }^{(27)}$. The Study 3 sought to motivate towards adoption of health promoting behaviors through a health promoting intervention from a specialist cancer nurse based on a SCP raising awareness to the importance of surveillance and healthy living ${ }^{(21)}$. The Study 10 concluded that a motivation boost for change may increase levels of physical activity on the $18 \%$ of cancer patients that did not increase their physical activity after nursing intervention ${ }^{(28)}$. The Study 4 analysed three studies that used motivational strategies to promote health behaviors, including motivational interviews, postcard prompts and telephone calls ${ }^{(22)}$. Study 6 also reported the use of motivational interviews to facilitate health behavior changes ${ }^{(24)}$. The Study 12 pointed out that, similarly to the lack of awareness, lack of motivation to change health behaviors is a barrier to cancer survival ${ }^{(30)}$.

As motivation, self-efficacy and educational partnership may be relevant for health behavior change. Authors from Study 8 suggested that an intervention directed at enhancing awareness and skills towards resource and self-efficacy increase and reduction of barriers may result in greater participation in health-promoting behaviors for cancer survivors $^{(26)}$. The Study 5 further recommended that patient-nurse educational cooperation may act as a motivator for health lifestyle practices and self-management ${ }^{(23)}$.

\section{Outcome ASSESSMENT MEASURES}

The purpose of the outcome assessment measure analysis was to identify the most important outcomes to include in a complex intervention. In this review, as an excessive heterogeneity between outcome assessment measures was observed, the authors decided to differentiate between primary and secondary outcomes. Health promoting behaviors were classified as primary outcomes and, accordingly, the Health Promoting Lifestyle Profile II was the only instrument used in more than one study ${ }^{(21,26)}$. In every other study, health behavior evaluation was divided by subjects. Physical activity was measured in metabolic equivalents of tasks (METs) ( $\mathrm{kcal} / \mathrm{kg} /$ week) using surveys inquiring about physical activity time, length and intensity (19), including the Godin Leisure-Time Exercise Questionnaire (GLTEQ) ${ }^{(28)}$ and the Physical Activity Questionnaire Short Form (IPAQ-SF) ${ }^{(24)}$. Diet was evaluated through previously validated questions about vegetable and fruit daily intake; dietary pattern was checked with a questionnaire based on the "Rules for National Cancer Prevention: Dietary Practice Guideline"(19); and effectiveness of dietary interventions was determined through the Fat and Fiber Behavior Questionnaire ${ }^{(20)}$ and the Food Frequency Questionnaire (FFQ) ${ }^{(24)}$. Posttraumatic growth was measured with the Post-traumatic Growth Inventory $(\mathrm{PTGI})^{(19)}$. Hospital Anxiety and Depression Scale (HADS) (19) and Distress Thermometer (adapted from the National Comprehensive Cancer Network Distress Thermometer for Patients) were used to assess distress and psychiatric disorders ${ }^{(20)}$. Smoking cessation was evaluated by a self-reported 7 -day point prevalence quit rating by smoking cancer patients ${ }^{(27)}$. Most relevant secondary outcomes were related to health perception and assessed through the European Organization for Research and Treatment of Cancer Quality of Life Questionnaire C30 (EORTC QLQ-C30) ${ }^{(19)}$, the General Health Index ${ }^{(21)}$, Quality of Life (SF-12) and Quality Adjusted Life Years (QALYs) ${ }^{(20)}$.

\section{Effectiveness}

Data retrieved from our review clearly highlights the success of nursing interventions in several health promotion behaviors.

The review performed on the Study 4, which aimed to identify effective interventions for multiple health behavior changes in cancer survivors and individuals at high risk of cancer, showed that eight studies $(n=8 / 10,80 \%)$ changed at least two health behaviors at the same time, including diet-related behaviors (namely fruit and vegetable intake), exercise and smoking and/or alcohol intake ${ }^{(22)}$.

Quantitative studies included in this review also revealed a significant health behavior change. The Study 10 strongly suggested that brief educational brochures emphasizing strategies to increase physical activity are well received, regardless of the message frame (gain-frame or loss-frame) and produce a significant physical activity increase among inactive cancer survivors (about $25 \%$ of previously inactive participants increased activity to national recommendation levels after one month) ${ }^{(28)}$. Among 488 responders to a questionnaire applied 
at least one year after RAVs by an oncology nurse, nearly 93\% found the SCP useful to identify healthy lifestyle practices and $97 \%$ made at least one positive lifestyle change ${ }^{(23)}$. Comparison of intervened with control group participants suggested that the Health Promotion intervention improved health promotion behaviors and self-efficacy ${ }^{(26)}$. The mediating variable, total Health-Promotion Lifestyle Profile II (HPLP II), changed significantly over time $(p<0.01)^{(26)}$. Only Study 1 showed that, although the Leadership and Coaching for Health (LEACH) program changed the rates of success in more than two of three primary outcomes (physical activity, dietary habits, and post-traumatic positive growth) from baseline to 3 and 12 months, that change was similar to the observed on the usual care group ${ }^{(19)}$.

\section{Cost effectiveness}

Only two of the considered studies analysed intervention cost effectiveness, but none disclosed intervention-related costs. Study 3 acknowledged that physical activity brochures can be easily distributed via email, incorporated into existing patient-teaching materials, or made available in patient' waiting areas ${ }^{(28)}$. The authors further emphasized that these strategies are promising because they do not require a lot of additional time or money ${ }^{(28)}$. In terms of value for cost, the Study 5 considered that an Oncology nurse is ideal to establish a SCP, considering the effectiveness of nurses in providing meaningful and cost-effective patient education about chronic diseases ${ }^{(23)}$.

\section{DISCUSSION}

Related to intervention procedures, the present analysis evidences that most contributions used SCT (1986), TTM (1983) and TPB (1991)) derive from other fields of knowledge besides nursing, namely health psychology. Several recent references to these models are found in literature, referring the benefits of nursing approaches and interventions towards health promotion ${ }^{(31-37)}$.

Besides these contributions, the Revised Health Promotion Model (RHPM) was also used and can be considered to support nursing interventions. Contrarily to other models, the RHPM is a nursing intervention model that supports nurses in understanding the main determining factor in health behaviors as a way to provide behavior counselling to promote healthy lifestyles ${ }^{(13)}$. Despite being a part of the SCT, it is useful to restructure protocols and nursing interventions through a nurse's perspective of holistic human functioning ${ }^{(13)}$. RHPM-based training is a useful model, prone to be used by healthcare providers to improve a number of health-promoting behaviors but also patients' perceived benefits and self-efficacy, commitment to action, interpersonal and situational influences, behavior-related affect and barriers $(\mathrm{p}<0.001)^{(38)}$. Recent use of this model by nurses for health promotion in different types of patients has been widely documented ${ }^{(39-41)}$. Nurse's role is to promote a positive environment for change, act as a catalyst for change, assist with various steps of the change process and increase individual's capacity to maintain change ${ }^{(13)}$.
Procedures results emphasizes how educational strategies become particularly relevant in health promotion interventions by nurses. It was interesting to realize that, similarly to results retrieved from this analysis, an integrative review about nurses' roles in health promotion practice determined that the most common health promotion intervention used by nurses is health education ${ }^{(42)}$. Health education intends to motivate individuals to accept a behavioral change process by informing and teaching them how to achieve a better health ${ }^{(43-44)}$. A rigorous data analysis allowed to realize that, to be successful, health education is usually combined with other strategies. Overall, this body of evidence suggests that only by identifying, acknowledging, concentrating on and developing individual strengths and environmental resources, can nurses help individuals improve their well-being ${ }^{(45)}$.

Study 3 and Study 5 reinforced the importance of framing nursing interventions within a personalized plan in the $\mathrm{SCP}^{(21,23)}$. The SCP offers essential information for patients as they progress along their cancer trajectory ${ }^{(46)}$. The SCP is also supported by the Institute of Medicine and National Research Council of the National Academies 2005 report. This report assumes that SCP is important to cancer survivorship and suggests that it includes "recommendations regarding preventive practices and how to maintain health and well-being"(47). A recent study also reviewed published studies investigating the perspective of several stakeholders (survivors, primary care providers and Oncology providers) on SCP and revealed that, according to survivors, providing information about ongoing care in a SCP would foster selfmanagement by helping them monitor late effects, adopt healthy behaviors, and get appropriate surveillance ${ }^{(48)}$.

As shown in results related to mechanisms of change, motivation is a key concept for health behavior change. Retrieved results are consistent with other relevant references in the literature pointing out that motivation has a good predictive power on health behaviors ${ }^{(49)}$, is a critical variable in maintaining change $\mathrm{e}^{(50)}$ and is the most significant stumbling block in health promotion and wellness ${ }^{(51)}$. On the other hand, the Study 8 attributed more importance to self-efficacy on health change than motivation ${ }^{(26)}$. Study 8 was supported by another manuscript witch stating that, unlike motivation, self-efficacy was a significant predictor in health-promoting behavior performance ${ }^{(52)}$.

The outcome assessment measures results display that there is a huge variety of data related to health promotion, showing that this is a multidimensional area, which cannot and should not be assessed out of any context.

Overall, results suggest that some correlation exists between effectiveness of nursing interventions and health behavior promotion, thus supporting the concept that health promotion by nurses can accomplish several positive health outcomes $^{(53-54)}$.

Our review has strengths and limitations. The main limitation concerns the inclusion of English and Portuguese language studies only. Other limitations are the fact that the quality of articles included was not evaluated (because this is not a JBI requirement for Scoping Reviews) and only 
twelve databases were used. On the other hand, because authors wanted to assess a broad range of information, the main strength of this review is the inclusion and analysis of recent studies addressing several disease stages and cancer types.

\section{CONCLUSION}

Throughout this analysis, it is possible to realise that nurses assume an important role in health promotion of cancer survivors and their autonomous interventions have been successful in changing health behaviors.

Results retrieved allow to infer characteristics of nursing interventions associated with health behavior promotion. Most studies described interventions focused on patient knowledge and awareness, particularly through health education activities lasting between 12 and 14 weeks. These studies frequently described group interventions, as well as private and virtual sessions lasting between 1 and 2.5 hours. However, it seemed unanimous that information, by itself, is not determinant for behavioral change, raising the need to incorporate reinforcement and incentive measures for this purpose. Most of those incentives occurred via telephone and had an estimated duration of 10 to 30 minutes. Moreover, it seems relevant to complement educational strategies with motivational ones, promoting self-efficacy. Indeed, motivation has been acknowledged as a key mechanism towards change, extremely relevant for development and maintenance of new health behaviors and, hence, for cancer patient health improvement.

Survivorship seems to be the perfect time for health promotion interventions, as it represents the moment when cancer patients feel liberated from managing treatmentrelated side effects and relieved that cancer treatment is over, but also lack the usual disease support and feel uncertain about their future.

This review allows to conclude that, due to their large spectrum of interventions, nurses can be considered health promoters by means of health education activities, essential to maintain cancer patients informed and promote the adoption of health behaviors. It is clear that, over time, nurses have earned the ability to help people manage their disease. However, the future requires development of specific skills to help people maintain their health status. Hence, this study represents an important contribution to other investigations, namely those dedicated at planning interventions in the field focused on health promotion after oncological disease. This study allows to define four key aspects for future investigation and opportunities to increase nursing's knowledge: (i) survivorship seems to be the perfect time to promote healthy lifestyle habits, as it is the moment when cancer patients feel liberated from managing treatment-related side effects; (ii) motivation is a key concept towards changing and maintaining health behaviors in cancer patients; (iii) nurses can be considered health promoters through development of health education activities, essential to keep survivors informed and promote awareness on the need to adopt health behaviors; (iv) nursing interventions are effective in promoting health behaviors through health education, supportive relationships and personalized care plans with individual goals.

\section{RESUMO}

Objetivo: Esta revisão tem como objetivo mapear e fornecer um panorama da literatura sobre estratégias e programas de intervenção de enfermagem que promovem comportamentos saudáveis em pacientes com câncer. Método: Uma revisão de escopo foi conduzida usando a estrutura metodológica desenvolvida pelo Instituto Joanna Briggs e PRISMA (Preferred Reporting Items for Systematic Review and Meta-analysis) extensão para revisões de escopo. Doze bancos de dados foram pesquisados (2012-2019). Os dados recuperados incluíram análises descritivas explorando as características metodológicas e os resultados dos estudos. Resultados: De 1589 estudos, 12 foram incluídos. A maioria dos estudos incluiu pacientes em período de sobrevivência $(n=10)$ e estratégias de intervenção selecionadas com foco no conhecimento e consciência do paciente $(\mathrm{n}=8)$. As sessões educacionais foram apoiadas por reforços de mudança comportamental e incentivos motivacionais. Apenas dois dos estudos considerados analisaram a efetividade do custo da intervenção, mas nenhum revelou custos relacionados à intervenção. Conclusão: As intervenções de Enfermagem são eficazes na promoção de comportamentos de saúde quando incluem a educação em saúde e o incentivo à mudança. A sobrevivência é o momento perfeito para a promoção da saúde. Os enfermeiros podem ser considerados promotores da saúde, por estimularem a educação para a saúde e aumentar a motivação dos sobreviventes.

\section{DESCRITORES}

Neoplasias; Enfermagem Oncológica; Promoção da Saúde; Educação em Saúde; Revisão.

\section{RESUMEN}

Objetivo: Esta revisión tiene como objetivo mapear y proporcionar una visión general de la literatura sobre estrategias y programas de intervención de enfermería que promueven conductas saludables en pacientes con cáncer. Método: Se realizó una revisión del alcance utilizando el marco metodológico desarrollado por el Instituto Joanna Briggs y PRISMA (Preferred Reporting Items for Systematic Review and Meta-analysis) extensión para revisiones de alcance. Se realizaron búsquedas en doce bases de datos (2012-2019). Los datos recuperados incluyeron análisis descriptivos que exploran las características metodológicas y los resultados de los estudios. Resultados: De 1589 estudios, se incluyeron 12. La mayoría de los estudios incluyeron pacientes en el período de supervivencia $(n=10)$ y estrategias de intervención seleccionadas que se centraron en el conocimiento y la conciencia del paciente $(\mathrm{n}=8)$. Las sesiones educativas fueron apoyadas por refuerzos de cambio de comportamiento e incentivos motivacionales. Solo dos de los estudios considerados analizaron la rentabilidad de la intervención, pero ninguno reveló costos relacionados con la intervención. Conclusión: Las intervenciones de enfermería son efectivas para promover comportamientos de salud cuando incluyen educación para la salud y fomentan el cambio. La supervivencia es el momento perfecto para la promoción de la salud. Los enfermeros pueden considerarse promotores de la salud, ya que fomentan la educación sanitaria y aumentan la motivación de los supervivientes.

\section{DESCRIPTORES}

Neoplasias; Enfermería Oncológica; Promoción de la Salud; Educación en Salud; Revisión. 


\section{REFERENCES}

1. Morounke S, Ayorinde J, Benedict A, Faduyile F, Adewale O, lyapo O, et al. Epidemiology and incidence of common cancers in Nigeria. J Cancer Biol Res. 2017;5(3):1105-12.

2. World Health Organization; International Agency for Research on Cancer. All cancers, GLOBOCAN 2018 [Internet] Geneva: WHO; 2018 [cited 2020 May 10]. Available from: https://gco.iarc.fr/today/data/factsheets/cancers/39-All-cancers-fact-sheet.pdf

3. World Health Organization. Global Health Estimates 2015: deaths by cause, age, sex, by country and by region, $2000-2015$ [Internet]. Geneva: WHO; 2016 [cited 2019 Oct 17]. Available from: http://www.who.int/healthinfo/global_burden_disease/en/

4. World Health Organization. Guide to cancer early diagnosis [Internet]. Geneva: WHO; 2017 [cited 2019 Oct 17]. Available from: https:// www.who.int/cancer/publications/cancer_early_diagnosis/en/

5. Agency for Healthcare Research and Quality. Medical Expenditure Panel Survey. Rockville; 2014.

6. Mayer D, Nasso S, Earp J. Defining cancer survivors, their needs, and perspectives on survivorship health care in the USA. Lancet Oncol. 2017;18(1):e11-e18. doi: http://doi.org/10.1016/S1470-2045(16)30573-3

7. Shilling V, Starkings R, Jenkins V, Fallowfield L. The pervasive nature of uncertainty: a qualitative study of patients with advanced cancer and their informal caregivers. J Cancer Surviv. 2017;11(5):590-603. doi: http://doi.org/10.1007/s11764-017-0628-x

8. Robinson L. Health promotion and cancer nursing. Eur J Oncol Nurs. 2000;4(3):135. doi: https://doi.org/10.1054/ejon.2000.0106

9. Weaver K, Forsythe, L, Reeve B, Alfano C, Rodriguez J, Sabatino S, et al. Mental and physical health-related quality of life among U.S. cancer survivors: population estimates from the 2010 National Health Interview Survey. Cancer Epidemiol Biomarkers. 2012;21(11):210817. doi: http://doi.org/10.1158/1055-9965.EPI-12-0740

10. American Cancer Society. Cancer treatment and survivorship facts \& figures 2014-2015. Atlanta: American Cancer Society; 2014.

11. Lin C. Health promotion for cancer patients: opportunities and challenges in cancer nursing; Cancer Nurs. 2016;39(5):339-40. doi: http:// doi.org/10.1097/NCC.0000000000000416

12. World Health Organization. Ottawa Charter for Health Promotion. Geneva: WHO; 1986.

13. Pender N, Murdaugh C, Parsons M. Health promotion in nursing practice. 7th ed. New York: Pearson Education; 2015.

14. Harding M. Health-promotion behaviors and psychological distress in cancer survivors; Oncol Nurs Forum. 2012;39(2):132-40. doi: http:// doi.org/10.1188/12.ONF.E132-E140

15. Coward D. Supporting health promotion in adults with cancer. Fam Community Health. 2006;29(1):52-60.

16. Craig P, Dieppe P, Macyntire S, Michie S, Nazareth I, Petticrew M.. Developing and evaluating complex interventions: the new medical research council guidance. Int J Nurs Stud. 2013;50(5):587-92. doi: http://dx.doi.org/10.1136/bmj.a1655

17. Peters MDJ, Godfrey CM, McInerney P, Soares CB, Khalil H, Parker D. The Joanna Briggs Institute reviewers' manual 2015: methodology for JBI scoping reviews. Adelaide: JBI; 2015.

18. Arksey H, O'Malley L. Scoping studies: towards a methodological framework. Int J Soc Res Methodol. 2005;8:19-32. doi: http://doi.org/ $10.1080 / 1364557032000119616$

19. Yun Y, Kim Y, Lee M, Sim J, Nam BH, Kim S, et al. "A randomized controlled trial of physical activity, dietary habit, and distress management with the Leadership and Coaching for Health (LEACH) program for disease-free cancer survivors." BMC Cancer. 2017;17(1):298-8. doi: https://doi.org/10.1186/s12885-017-3290-9

20. Eakin E, Hayes S, Haas M, Reeves M, Vardy J, Boyle F, Hiller J, et al. "Healthy living after cancer: a dissemination and implementation study evaluating a telephone-delivered healthy lifestyle program for cancer survivors." BMC Cancer. 2015;15:992. doi: https://doi.org/10.1186/ s12885-015-2003-5

21. Gates P, Seymour J, Krishnasamy M. Insights into the development of a nurse-led survivorship care intervention for long-term survivors of Hodgkin lymphoma. Aust J Cancer Nurs. 2012;13(1):4-10.

22. Green A, Hayman L, Cooley M. Multiple health behavior change in adults with or at risk for cancer: a systematic review. Am J Health Behav. 2015;39(3):380-94. doi: https://doi.org/10.5993/AJHB.39.3.11

23. Rosenberg C, Flanagan C, Brockstein B, Obel J, Dragon L, Merkel D, et al. Promotion of self-management for post treatment cancer survivors: evaluation of a risk-adapted visit. J Cancer Surviv. 2016;10(1):206-19. doi: https://doi.org/10.1007/s11764-015-0467-6

24. Anderson D, Seib C, Tjondronegoro D, Turner J, Monterosso L, McGuire A, Porter-Steele J, et al. The women's wellness after cancer program: a multisite, single-blinded, randomised controlled trial protocol. BMC Cancer. 2017;17(1):98. doi: https://doi.org/10.1186/s12885-017$3088-9$

25. Tramm R, McCarthy A, Yates P. Using the precede-proceed model of health program planning in breast cancer nursing research. J Adv Nurs, 2012;68(8):1870-80. doi: https://doi.org/10.1111/j.1365-2648.2011.05888.x

26. Meraviglia M, Stuifbergen A, Parsons D, Morgan S. Health Promotion for Cancer Survivors: adaptation and Implementation of an Intervention. Holist Nurs Pract. 2013;27(3):140-7. doi: https://doi.org/10.1097/HNP.0b013e31828a0988

27. Li W, Chan S, Wang K, Lam T. Helping cancer patients quit smoking by increasing their risk perception: a study protocol of a cluster randomized controlled trial. BMC Cancer. 2015;15:490. doi: https://doi.org/10.1186/s12885-015-1496-2

28. Hirschey R, Lipkus I, Jones L, Mantyh C, Sloane R, Demark-Wahnefried W. Message framing and physical activity promotion in colorectal cancer survivors. Oncol Nurs Forum. 2016;43(6):607-705. doi: https://doi.org/10.1188/16.ONF.43-06AP

29. Loprinzi P, Lee H. Rationale for promoting physical activity among cancer survivors: literature review and epidemiologic examination. Oncol Nurs Forum. 2014;41(2):117-25. doi: https://doi.org/10.1188/14.ONF.117-125 
30. Demark-Wahnefried W, Schmitz K, Alfano C, Bail J, Goodwin P, Thomson C, Bradley D, et al. Weight management and physical activity throughout the cancer care continuum. CA Cancer J Clin. 2017;68(1):64-89. doi: https://doi.org/10.3322/caac.21441

31. Cadet TJ, Berrett-Abebe J, Burke SL, Bakk L, Kalenderian E, Maramaldi P. Evidence-based health promotion in nursing homes: a pilot intervention to improve oral health. Educ Gerontol. 2016;42(5):352-60. doi: http://doi.org/10.1080/03601277.2015.1121754

32. Valle CG, Tate DF, Mayer DK, Allicock M, Cai J. Exploring mediators of physical activity in young adult cancer survivors: evidence from a randomized trial of a facebook-based physical activity intervention. J Adolesc Young Adul. 2015;4(1):26-33. doi: http://doi.org/10.1089/ jayao.2014.0034

33. Joseph RP, Daniel CL, Thind H, Benitez T, Pekmezi D. Applying psychological theories to promote long-term maintenance of health behaviors. Am J Lifestyle Med. 2016;10(6):356-68. doi: http://doi.org/10.1177/1559827614554594

34. Joseph RP, Keller C, Adams M, Ainsworth BE. Print versus a culturally-relevant Facebook and text message delivered intervention to promote physical activity in African American women: a randomized pilot trial. BMC Women's Health. 2015;30:1530. doi: http://doi.org/10.1186/ s12905-015-0186-1

35. Menezes M, Bedeschi LB, Santos LD, Lopes AS. Interventions directed at eating habits and physical activity using the transtheoretical model: a systematic review. Nutr Hosp. 2016;33(5):586. doi: http://doi.org/10.20960/nh.586

36. Jemmott J, Stephens-Shields A, O'Leary A, Jemmott LS, Teitelman A, Ngwane Z, et al. Mediation of effects of a theory-based behavioral intervention on self-reported physical activity in South African men. ISRN Prev Med. 2015;72:1-7. doi: http://doi.org/10.1016/j. ypmed.2014.12.022

37. Forbes C, Blanchard C, Mummery W, Courneya K. Prevalence and correlates of strength exercise among breast, prostate, and colorectal cancer survivors. Oncol Nurs Forum. 2015;42(2):118-27. doi: http://doi.org/10.1188/15.ONF.42-02AP

38. Khodaveisi M, Omidi A, Farokhi S, Soltanian AR. The effect of Pender's health promotion model in improving the nutritional behavior of overweight and obese women. Int J Community Based Nurs Midwifery [Internet]. 2017 [cited 2019 Dec 17];5(2):165-74. Available from: https://www.ncbi.nlm.nih.gov/pmc/articles/PMC5385239/

39. Gama G, Trezza M, Rodrigues P, Alves K. Health promotion in pregnancy: enforcement of Nola Pender theory on prenatal care. J Nurs UFPE. 2016;1:104428-31. doi: http://doi.org/10.5205/reuol.9284-81146-1-SM.1005sup201638

40. McCutcheon T, Schaar G, Parker KL. Pender's health promotion model and HPV health-promoting behaviors among college-aged males: concept integration. J Theory Constr Test. 2016;10(1):12-9.

41. Xingjuan T, Chow S, Wong F. A nurse-led case management program on home exercise training for hemodialysis patients: a randomized controlled trial. Int J Nurs Stud. 2015;52(6):1029-41. doi: http://doi.org/10.1016/j.ijnurstu.2015.03.013

42. Kemppainen V, Tossavainen K, Turunen H. Nurses' roles in health promotion practice: an integrative review. Health Promot Int. 2013;28(4):490-501. doi: https://doi.org/10.1093/heapro/das034

43. Whitehead D. Health promotion and health education: advancing the concepts. J Adv Nurs. 2004;47(3):311-20. doi: http://doi.org/10.1111/ j.1365-2648.2004.03095.x

44. Raingruber B. Contemporary health promotion in nursing practice. Philadelphia: Jones \& Bartlett; 2014.

45. Leddy S. Health promotion: mobilizing strengths to enhance health wellness, and well-being. Philadelphia: FA Davis; 2006.

46. Pirschel C. Creating and sustaining survivorship care plans in practice [Internet]. Pittsburgh (PA): Oncology Nursing Society Voice; 2017 [cited 2019 Dec 17]. Available from: https://voice.ons.org/news-and-views/survivorship-care-plans-in-practice

47. Hewitt M, Greenfield S, Stovall E. From cancer patient to cancer survivor: lost in transition. Washington: Institute of Medicine and National Research Council of the National Academies; 2006.

48. Salz T, Oeffinger K, McCabe M, Layne T, Bach P. Survivorship care plans in research and practice. CA Cancer J Clin. 2012;62(2):101-7. doi: http://doi.org/10.3322/caac.20142

49. Almeida C. Motivação e comportamentos de saúde, relação com qualidade de vida, em adultos da comunidade [dissertação]. Porto: Universidade do Porto, Faculdade de Psicologia e Ciências da Educação; 2013.

50. Ryan R, Deci E. Self determination theory and the facilitation of intrinsic motivation, social development, and well-being. Am Psychol. 2000;55(1):68-78. doi: http://doi.org/10.1037//0003-066x.55.1.68

51. Seifert CM, Chapman LS, Hart JK, Perez P. Enhancing intrinsic motivation in health promotion and wellness. Am J Health Promot. 2012;26(3):TAHP1-12. doi: http://doi.org/10.4278/ajhp.26.3.tahp

52. Fisher K, Kridli SA. The role of motivation and self-efficacy on the practice of health promotion behaviors in the overweight and obese middle-aged American women. Int J Nurs Pract. 2014;20(3):327-35. doi: http://doi.org/10.1111/ijn.12155

53. Bosch-Capblanc X, Abba K, Prictor M, Garner P. Contracts between patients and healthcare practitioners for improving patients' adherence to treatment, prevention and health promotion activities, Cochrane Database Syst Rev. 2007;(2):CD004808. doi: http://doi. org/10.1002/14651858.CD004808.pub3

54. Keleher H, Parker R, Abdulwadud O, Francis K. Systematic review of the effectiveness of primary care nursing, Int J Nurs Pract. 2009;15(1):16-24. doi: http://doi.org/10.1111/j.1440-172X.2008.01726.x 